\section{ENGENHANDO NOSSO FUTURO: ARTE E SOCIEDADE}

\section{Cleomar Rocha e Suzete Venturelli}

CIDADE INTELIGENTE Os conceitos e os avanços em torno de "cidade inteligente" se concentram basicamente nos benefícios envolvendo a interatividade, energia, ecologia, mobilidade, arquitetura responsável, sociabilidade e cidadania. Uma das definições da cidade inteligente é, também, "cidade que depende das TICs para obter gestão mais eficiente". Entretanto, por trás desse conceito encontra-se a cidade, a metrópole como um ecossistema baseado em fluxos digitais de informação e, mais amplamente, na criatividade digital em prol da qualidade de vida. Atualmente, $50 \%$ da população mundial vive nas cidades. Em 2050, essa porcentagem aumentará para 70\%. Cresce igualmente a importância da participação da arte nesse processo de urbanização. A arte sempre foi parte integrante da cidade desde sua origem e acompanha os processos sociais, acelerados desde o início deste século. Este texto apresenta projetos desenvolvidos pelos laboratórios Media Lab em Goiânia e Brasília, de intervenções artísticas que pensam a cidade. Nesse sentido, importa pensar a cidade como ambiente de socialização, em que ética e estética não apenas podem, mas essencialmente participam do conceito de cidades inteligentes, ao se vincularem, pelas possibilidades de interações sociais, às relações humanas e valorização do meio ambiente.

Ainda que a temática de cidades inteligentes esteja fortemente ligada às tecnologias e à internet, como se verifica em autores como Castells [1] e Lévy [2], ao definirem um futuro para a sociedade, há de se considerar alguns outros aspectos, como sustentabilidade [3], ecologia e uma profunda mudança nos meios industriais [4] e comerciais. Essas concepçôes criam um novo mapa das cidades, construído a partir de sua relevância na concepção e construção do futuro [5]. A cidade inteligente é, sem dúvida, digital [6], mas não apenas isso. Há de se vislumbrar valores construídos sobre princípios da sensibilidade, das poéticas e estéticas, traços definidores da condição humana.

DE POLIS E MEGALÓPOLIS A migração populacional da zona rural para os centros urbanos é notória, com maior desenvolvimento no século XX [7], que concentrou também a migração de habitantes de cidades menores para os grandes centros. A ideia de megalópole

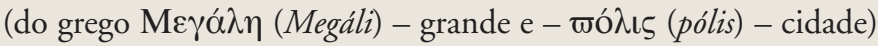
vem daí, designando regiōes metropolitanas com mais de 10 milhões de habitantes.

A densidade demográfica, que se deve ao aumento populacional e ao desenvolvimento científico e tecnológico, também deve seu legado à crescente oferta de emprego em áreas de franco desenvolvimento nas cidades, inclusive para manutenção das próprias cidades, e da redução dos postos de trabalho nas áreas rurais, pela tecnologização do setor, passando a depender mais de aparatos tecnológicos que de trabalhadores braçais. O fruto dessa aglomeração [8] é experimentado por gargalos enfrentados pelas cidades, nos diversos campos, com maior evidência para a mobilidade, a saúde, o meio ambiente, a educação, a segurança, a infraestrutura em geral, a cultura e o lazer.

Diferentemente do que pensam alguns, uma cidade não é caracterizada por um conjunto de ruas e avenidas com suas casas e edifícios. Uma cidade é mais um espaço de exercício de cidadania, efetivado por seus cidadãos. A intrínseca relação entre cidade, cidadão e cidadania justifica o mesmo radical, na formação das palavras.

E se a presença do cidadão caracteriza o que denominamos de cidade, esta deve possuir os qualificadores para se tornar o espaço ótimo para a vida social, o que inclui a arte, como atributo humano para se alcançar a plenitude, a transcendência. De modo complementar ao que ocorre no reino Animalia, em que a vida se completa na reprodução como estratégia de continuidade dos genes, no humano a busca pela transcendência nos distingue, fazendo a sensibilidade e a cognição sobrepujarem a carga genética, em uma contribuição social maior. É nessa condição que o lócus social impera.

A cidade, como espaço ótimo de sociabilidade [9], passa a representar um organismo social vivo, com todas as características que a sociedade mantém. A arte, nesse meio, se coaduna com a ciência e a tecnologia, criando um contexto social fértil para o pleno exercício da vida da espécie. Essa condição responde o porquê do surgimento das megalópolis, vórtices da vida social contemporânea.

DE LABORATÓRIOS MULTIDISCIPLINARES [10] Uma visada diacrônica da história da civilização revela que a especialização, e mesmo o distanciamento entre arte e ciência, é advento recente. Fruto de um adensamento epistemológico que gera milhares de informações, a especialização das áreas de conhecimento corroboram para o crescente volume de detalhamento, tornando o ser humano incapaz de reter tanta informação, como ocorria até o renascimento, último movimento que pregava o holismo intelectual como uma perspectiva epistêmica [11].

A tecnologia, filha pródiga da ciência, faz ressurgir o ideário renascentista, tornando-se elo para os diversos interesses humanos. Não por acaso, o encontro entre arte e tecnologia fez reunir artistas e cientistas, com contaminações de suas áreas de interesse, derivando daí as perspectivas de conhecimento e articulação das áreas. Das imbricações surgidas, um novo modelo de laboratório talvez seja o mais instigante: os laboratórios multiusuários.

No mundo inteiro, esse tipo de laboratório busca contribuir para dinâmicas interdisciplinares, ao se abrir para equipes multidisciplinares. O Media Lab do MIT [12] (Massachusetts Institute of Technology), por exemplo, concentra pesquisadores e pesquisas de várias áreas de conhecimento, em práticas interdisciplinares. O ZKM [13] (Zentrum für Kunst und Medien), da Alemanha, de igual modo articula interesses de pesquisadores de várias partes do mundo, em propostas interdisciplinares que orbitam a arte e a tecnologia. Ainda 
que tenham vários nomes e focos, o lugar de pretensa neutralidade da mídia e tecnologia tem vigorado como nominação usual, tendo na arte o elemento articulador para as equipes, dada a vinculação dela com a experimentação do novo e sua liberdade de expressão, tornando-se campo aberto para prospecçôes de criatividade e inovação [14].

No Brasil, os Media Labs - laboratórios de mídia - fazem escola, adotando uma estrutura física e organizacional flexível, capaz de abarcar interesses diversos e, mais relevante ainda, testar soluções tecnológicas que nascem de mentes inventivas e partem para contextos sociais, na forma de intervençôes artísticas, repousando em aplicações mercadologicamente relevantes - ainda que a exploração comercial não tenha o peso capitalista de fazer surgir novos milionários.

O modelo foi baseado no Media Lab do MIT, ganhando tons diferenciados em outros países, principalmente naqueles em que a arte tornou-se o carro-chefe da criação, como o Media Lab Prado [15] e o Media Lab / BR [16]. Em terras tupiniquins, a Universidade Federal de Goiás (UFG) foi pioneira ao adotar o nome e caracterizar o laboratório como espaço multiusuário. O Media Lab / UFG [17] foi idealizado em 2008, tendo sido formalmente constituído como laboratório multiusuário em 2009, pelo professor Cleomar Rocha. Em 2015, a Universidade Federal do Sul e Sudeste do Pará (Unifesspa) criou seu Media Lab [18] aos moldes do Media Lab / UFG, tendo o professor Teófilo Augusto como mentor. Os dois laboratórios se vincularam formando o Media Lab / BR. Em 2016, o Media Lab / UnB [19], da Universidade de Brasília (UnB), que até então respondia pelo nome de Midialab, juntou-se ao Media Lab / BR, assumindo a identidade visual e administrativa do grupo, com práticas multiusuário e multidisciplinar, sob o comando da professora Suzete Venturelli. Os três laboratórios passaram a compartilhar o mesmo ideário e a mesma base visual e a articular várias de suas atividades e programas. As atividades colaborativas e experimentais formam o percurso que conduz à inovação, nesses laboratórios, como nos lembra Fonseca:

(Os laboratórios) nos situam necessariamente em dinâmicas de produção coletiva e inovadora da realidade, mais do que nas lógicas de registro e análise em si. O laboratório, portanto, remete ao design, à experimentação e à colaboração" [20, p. 61].

O Media Lab / BR é tido como referência internacional [21] de articulação em pesquisa e produção de inovação, com forte acento na produção de arte e design, não se desvinculando dos contextos urbanos em que atuam.

ARTE, DESIGN E TECNOLOGIA NO CONTEXTO URBANO Os Media Labs, como um todo e em todo o mundo, se vinculam ao contexto urbano em que estão instalados, tendo profícua articulação com os atores e atividades locais, além de vínculos e abrangência internacional. $\mathrm{O}$ Media Lab Prado, Helsinki [22], MIT, dentre outros, são responsáveis por ativar circuitos comerciais e artísticos, com elaboração inventiva e inovativa em seus contextos de atuação, apresentando resultados em exposições, feiras e eventos, reverberando suas ações internacionalmente. A seguir citamos alguns trabalhos realizados em colaboração nos Media Labs da UnB e da UFG.

Wikinarua Wikinarua [23] é uma rede social que compreende conexão entre redes a partir da utilização de dispositivos móveis, como celulares, com tecnologia de realidade urbana aumentada (RUA) - software criado para que cada indivíduo, localizado em qualquer parte do Brasil, incluindo os de comunidades isoladas como quilombolas, indígenas ou outras, possa modificar e intervir no seu contexto urbano e/ou meio ambiente, por meio da arte com imagens, sons, animações e textos. Essa rede apresenta como forma de interativismo a construção de uma cartografia colaborativa, na qual são apresentadas as imagens, vídeos e outras informações inseridas por seus membros. A rede social é composta por quatro serviços principais: i) cartografia colaborativa com blogmaps; ii) ciber-rádio e ciberstreamtv; iii) software para dispositivo móvel, denominado de realidade urbana aumentada (RUA); e iv) enciclopédia (wiki) e um gamearte para dispositivo móvel denominado Cyber Ton Ton, em realidade aumentada. Além dos serviços principais, que visam a inclusão social pela arte, o Wikinarua contém os 12 protótipos desenvolvidos com apoio do prêmio XPTA.LAB 2009, do Ministério da Cultura / Cinemateca do Estado de São Paulo. Na economia criativa, a rede busca a inclusão social, a sustentabilidade e a inovação na diversidade cultural brasileira.

Por definição, uma rede social é um conjunto de entidades sociais com indivíduos ou organismos sociais conectados por relações criadas a partir de interações sociais. Com o advento da Web 2.0, novas possibilidades surgiram e o mais importante nessa proposta é que o usuário participa da sua construção, com novos conteúdos que levarão à formação de novos grupos. A criação do Wikinarua demonstra o valor dado à mobilidade em conexão como principal fator na constituição do sujeito da atualidade, que vive seu tempo. Aqui se valida a perspectiva de Paul Milgran do continuum da virtualidade ampliada (VA) e da realidade aumentada (RA), pelo potencial do virtual digital de se incrustar no físico e propiciar ações humanas, atingindo, respectivamente, os extremos de experiências virtuais pela evasão do mundo físico e o retorno à fisicalidade no ambiente aumentado virtualmente. É a realidade aumentada, misturada. A coexistência no digital e físico da RA, realidade misturada $(\mathrm{RM})$, realidade diminuída $(\mathrm{RD})$ off-line ou on-line resultante de interfaces locativas, tecnologias sencientes e pervasivas e computação ubíqua em dispositivos handless e interfaces móveis caracterizam a existência cíbrida. 
Projeto expográfico - Museu Casa de Cora Coralina Já o projeto expográfico para o Museu Casa de Cora Coralina [24] foi concebido e realizado pela equipe do Media Lab / UFG, a partir de um convite do museu. Para tal, partiu-se de um conceito de poetizar a casa, devolvendo a ela os versos de sua ilustre moradora. A utilização da poesia coralina como elementos da casa teve como principal objetivo a mudança da experiência do visitante, que passa a encontrar os poemas, apresentados singularmente, com auxílio de tecnologia. A cozinha, por exemplo, ganhou versos no vapor que sai das panelas, revelando que há poesia no ar. $\mathrm{Na}$ bica, além da água fresca, correm versos, que banham a cidade da velha casa da ponte. Na parede do quarto de escrita, feita de barro, os versos bailam e se dissolvem na estrutura da casa. E assim se faz o triângulo da vida: com versos na água, no ar e na terra. A equipe multidisciplinar responsável pelo projeto foi composta por músicos, cientistas da computação, engenheiros, artistas visuais, designers, historiadores e literatos, com a disposição de mudar a experiência do trabalho em um laboratório multiusuário, e a experiência de se deparar com o trabalho resultante desse primeiro.

O projeto expográfico resultou em um aumento de $38 \%$ no número de visitantes, além de conseguir mídia espontânea em jornais, TVs e revistas. Patrocinado pela Caixa Econômica Federal, a partir de edital, o projeto foi contemplado novamente na edição seguinte do edital, com novas açôes, agora sonoras, para o museu. O êxito do projeto pode ser verificado no impacto gerado, seja de público, seja de engajamento de uma equipe multidisciplinar trabalhando em prol de um objetivo complexo, com vários saberes, sabores e signos envolvidos.

Cinelab O projeto Cinelab, realizado pela equipe do Media Lab / UFG, explora o universo das grandes projeçôes em espaços abertos. Videomapping, curtas e longas metragens, o conteúdo projetado se articula com os locais em que ocorrem a projeção, bem como ao público. Desde produçôes audiovisuais do próprio laboratório e seus parceiros, até efeitos específicos baseados em mapeamento videográfico, a tônica do projeto é explorar os espaços urbanos a partir de imagens dinâmicas. Com efeito, em algumas ediçôes é possível notar construçôes mais elaboradas, como as projeçôes de olhos e boca em estátuas, na cidade de Goiás, fazendo com que as próprias estátuas contassem as proezas e agruras das personalidades que elas representam. Esse experimento, realizado durante o Festival Internacional de Cinema e Vídeo Ambiental, edição 2016, compôs a programação oficial do evento, e foi resultado de um workshop conduzido por Cleomar Rocha.

Em outra edição, realizada em Goiânia, também em 2016 , uma imagem de Pedro Ludovico foi apresentada na forma de videomapping. Na imagem, o fundador da capital goiana aparece em uma janela, olha o ambiente externo e volta a entrar na sala. A imagem foi projetada em um edifício antigo do centro da cidade, em um evento chamado Cinema na Calçada. O resultado da pro-

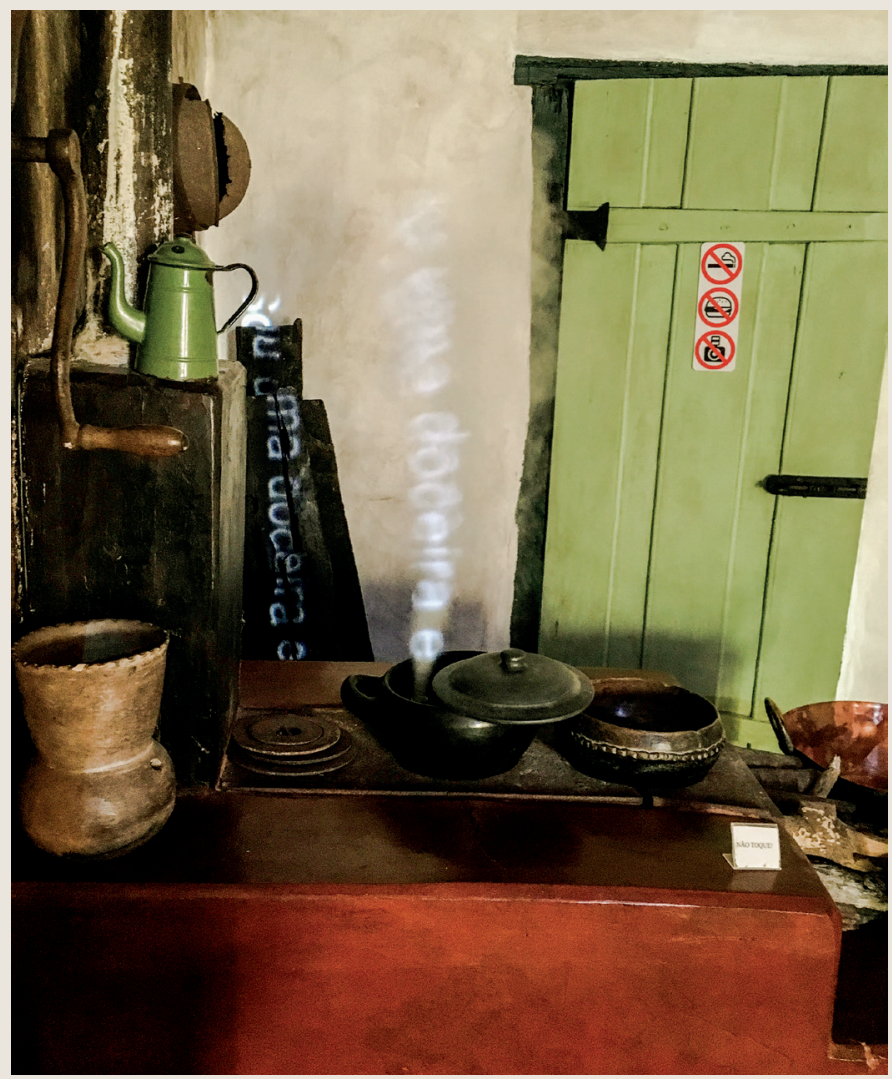

Figura 1. Detalhe do projeto expográfico do Museu Casa de Cora Coralina. Fonte: Media Lab / UFG

jeção se assemelhava, poeticamente, a um túnel do tempo, em que Pedro Ludovico retorna à cidade que criou para olhá-la pela janela. Tempo e espaço formaram o fio condutor da intervenção, que usou a tecnologia como condição operacional do trabalho.

Ciurbi O projeto Ciber Intervenção Urbana Interativa (Ciurbi) [25], do Media Lab / UnB, visou a produção no contexto da arte ativista em forma de açōes, buscando diminuir as diferenças sociais. Foi contemplado pelo edital Conexão Artes Visuais, de 2010, quando recebeu o patrocínio da Petrobrás realizado pela Funarte. Como citado no livro Arte computacional [26], a proposta se caracteriza como arte pública, que se apropria do espaço urbano, com projeçōes interativas sobre a arquitetura. $\mathrm{O}$ grafite acontece com a participação de membros da rede social Twitter, ao digitarem no início ou no final de seus comentários a palavra @ciurbi. O texto então é convertido em partículas animadas e sonoras que são projetadas em tempo real. Cada palavra é visualizada, e o público presente pode interagir enviando seu tweet pelo celular, inclusive no local onde ocorre o Ciurbi. O grafite interativo é formado por palavras coloridas animadas e sons, como partículas que se dissolvem no ar. A proposta intervém no espaço urbano numa antiga prática de apropriação da 
cidade, por ativistas políticos e artísticos, que ocorreu em diferentes épocas, culturas e sociedades. O diferencial nesse trabalho está na busca da intersecção entre arte, ciência e tecnologia, bem como na transversalidade com a performance, assim como no estabelecimento de diálogo entre o grafite e a arquitetura. Vários Ciurbis, como costumamos denominar as ações, já foram realizadas em cidades do Distrito Federal, como Brasília (na Universidade de Brasília, no Teatro Nacional e no Museu Nacional (Figura 2), Taguatinga e Ceilândia, cidades do entorno. Outras ciberintervençôes aconteceram em Santa Maria (RS), na Universidade Federal de Santa Maria, e na cidade de Aix-en-Provence, na França, especialmente realizada com a comunidade da École Supérieure d'Art.

Tijolo Esperto Outra obra, intitulada Tijolo Esperto [27], realizada no Media Lab / UnB, é o resultado de uma pesquisa premiada pelo edital Arte Cibernética do Itaú Cultural em 2009. Consiste numa parede interativa construída a partir da ideia de aplicação de algoritmos genéticos numa matriz luminosa de tijolos interativos, que funciona por um sistema constituído por LEDs (light-emitting diodes), diodos emissores de luz que, quando energizados positivamente, emitem luz visível, através da qual imagens e animaçôes podem ser visualizadas.

Esse projeto ilustra a preocupação da equipe de estudantes e professores em explorar instâncias do habitat interativo por meio da prática da experimentação dos meios digitais no ambiente construído, unindo vida artificial e vida de carbono. A proposta adequa-se às iniciativas de integrar as experiências artísticas nos espaços urbanos. As peças dos tijolos criados poderão servir como material interativo na construção de outros espaços arquitetônicos, reconfigurando a noção de parede, superfície e suporte. A possibilidade de reordenar os tijolos em tamanhos e formas variadas torna o projeto aberto a múltiplas composiçôes. Poeticamente, o projeto integra-se no campo de uma arte inserida no espaço que a cerca, preocupado com o meio ambiente. A proposta poética também se concentra na produção de conhecimento acerca dos processos interativos que contribuem para o desenvolvimento de softwares e hardwares livres, como linguagem e meio artísticos. Essa produção contribui para a criação de espaços físicos, artísticos, habitáveis, oferecendo uma realidade conectada entre sistemas naturais e artificiais. Tijolo Esperto possibilita entender as atribuiçóes e qualificaçōes de arquitetos, designers e artistas em projetos que exigem uma aproximação transdisciplinar, envolvendo parcerias com outros campos - em particular com a engenharia mecatrônica, a ciência da computação e as artes -, procurando estabelecer relações que explorem novas demandas e ferramentas para a arte computacional.

O tópico principal do projeto foi trabalhar com o desenvolvimento de objetos inteligentes que possam ser programados de acordo com um algoritmo específico, que permite a interação. $\mathrm{O}$ objetivo consistiu na concepção de um tijolo translúcido, no qual as superfícies são cobertas internamente por uma matriz de LEDs.

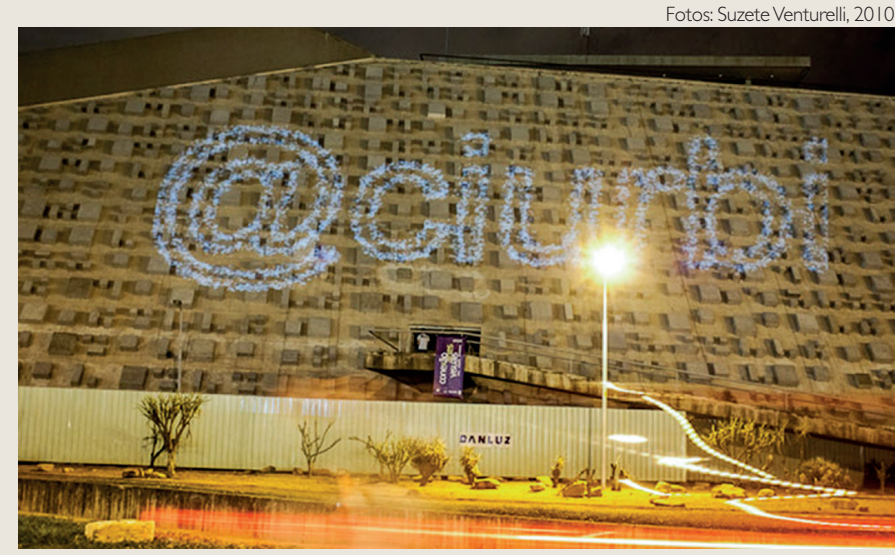

Figura 2. Ciurbi, Fachada do Teatro Nacional, Brasília - DF.

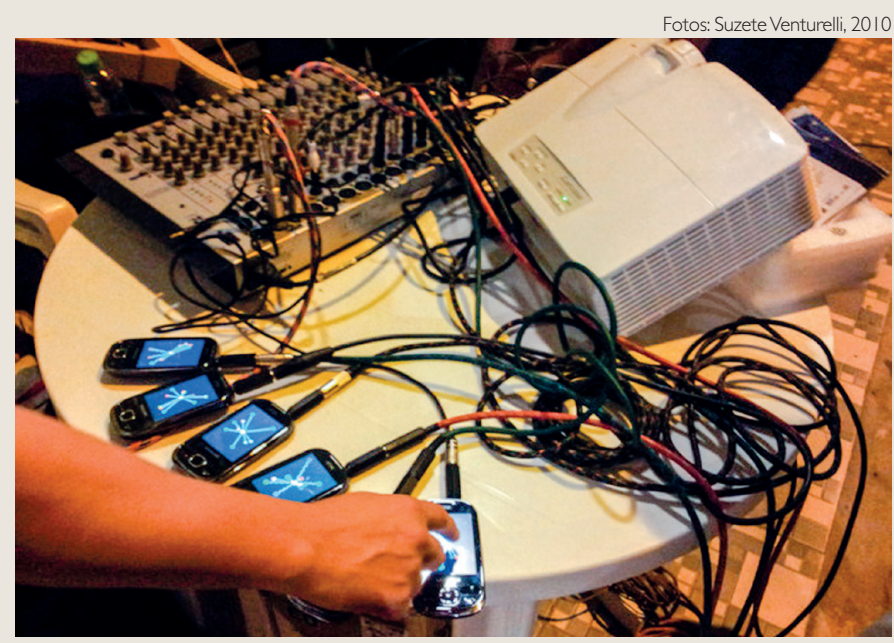

Figura 3. Geopartitura, intervenção urbana realizada na cidade de Taguatinga/DF. 2011

Cada tijolo se comunica com os demais tijolos dispostos, formando uma parede sistêmica capaz de exibir imagens maiores e mais complexas, por meio da intercomunicação dos vários tijolos e da interação com o público. Tijolo Esperto não se apropria de um espaço já existente da arquitetura, mas comporta-se como uma arquitetura tecnológica, um objeto interativo artístico que contém, ao mesmo tempo, suporte e superfície. Dessa forma, ele permite tanto a construção de objetos artísticos interativos quanto a construção de objetos arquitetônicos, pela conexão entre os tijolos e a criação de imagens pela presença do público interator.

Geopartitura O projeto Geopartitura [28] envolve a escrita musical, tendo como referência a arte computacional e a música eletroacústica, assim como a interatividade recorre à mídia locativa e móvel para a criação coletiva georreferenciada de um concerto computacional, envolvendo inclusive a visualização espaço-temporal da partitura e dos sons individuais, editados em tempo real em forma de cordas sonoras que vibram ao detectar a aproximação dos dispositivos móveis, como 
celulares. A interatividade e a participação criativa ocorreram em espaços públicos, como ciberintervenção urbana e tecnoperformance.

O projeto apontou para questôes emergentes envolvendo música, geografia e dispositivos móveis para permitir a criação coletiva georreferenciada de um concerto multimídia em tempo real. O sistema formado por software e dispositivos móveis permitiu a apresentação de um concerto multimídia cuja composição foi realizada ao vivo e em tempo real, por pessoas conectadas ao sistema pelos seus celulares (Figura 3).

O projeto teve como referência as ideias das marcações sonoras, oriundas da música eletroacústica e da música computacional, que historicamente romperam as fronteiras da música tradicional para buscar a interatividade pela participação do público. Geopartitura teve como objetivo proporcionar a execução de um concerto em tempo real coletivo, com música e imagem interagindo simultaneamente com pessoas portadoras de celulares que fossem detectadas pelo sistema por meio de Bluetooth, especificação industrial para áreas de redes pessoais sem fio (wireless personal area networks - PANs). O Bluetooth provê uma maneira de conectar e trocar informaçôes entre dispositivos como telefones celulares, notebooks, computadores, impressoras, câmeras digitais e consoles de videogames digitais por meio de uma frequência de rádio de curto alcance globalmente não licenciada e segura. As especificações do Bluetooth foram desenvolvidas e licenciadas pelo Bluetooth Special Interest Group. Outro aspecto importante do sistema é que os celulares devem conter global positioning system (GPS), ou, em português, sistema global de posicionamento. Esse é o principal sistema de localização e navegação utilizado atualmente no mundo, baseado em um sistema de 24 satélites estadunidenses, que conseguem observar todos os pontos do planeta.

Por meio do sistema, o interagente visualiza, em forma de projeção no espaço urbano, uma cartografia que surge a partir das conexões de todos os indivíduos detectados pelo sistema em tempo real. Essas cordas produzem sons quando tocadas. Poeticamente, Geopartitura está relacionado à existência de um ritmo no universo do conhecimento que conduz a música e a imagem em suas diferentes formas de manifestação. A palavra "geopartitura" tem origem na junção das palavras geografia e partitura. A geografia é a ciência que estuda o espaço, ou seja, busca o significado dos lugares; sendo assim, contribui significativamente com a sociedade na reorganização de seus espaços e de suas formas de interação com o ambiente.

CONSIDERAÇÕES FINAIS O estar no mundo, por si só, estabelece o vínculo necessário para que o fazer poético se vincule ao lugar como estratégia de encantamento social. As intervenções urbanas, ao extrapolarem os locais in situ, aqueles destinados estritamente à produção artística, converte a própria cidade, seus prédios, museus e ruas em espaços para a arte. O questionamento de a arte caber em uma única condição espacial é a base para a exploração dos espaços ex situ, ao tempo em que identifica o humano, e não espaços físicos, como os destinatários das ações e objetos estéticos.
Partindo desse princípio, de que o lugar da arte é o lugar do humano, abrem-se as perspectivas de apresentação e fruição artísticas. De outro modo, ao identificar que as cidades são a base da sociedade contemporânea, não haverá de ter espaço melhor que elas para introduzir o pulsar da arte, que tem seu coração nos objetos estéticos, nas suas veias espalhadas pelas várias mentes que formam o círculo mágico e transcendente do fazer poético.

As cidades encerram espaços do convívio e da cultura, ambientes ideais para a proliferação e o cultivo da urbanidade e da civilidade, cujo modelo é forjado, também, pela arte. Nesse sentido, não há de se restringir a discussão de cidades inteligentes ao âmbito tecnológico, que não responde, isoladamente, pelas premissas de inteligência instalada nas cidades. $O$ primeiro passo para se construir uma cidade inteligente, e o maior deles, é desenvolver pessoas inteligentes, sensíveis à própria condição de uso da tecnologia e à condição de pertencimento, construída pela estética, de uma comunidade.

Cleomar Rocha é professor associado na Universidade Federal de Goiás. Coordenador do Media Lab / BR e pesquisador produtividade do CNPq.

Suzete Venturelli é professora titular na Universidade de Brasilia. Coordenadora do Media Lab / UnB e pesquisadora produtividade do CNPq.

\section{NOTAS E REFERÊNCIAS}

1. Castells, M. A galáxia da internet: reflexões sobre a internet, negócios e a sociedade. Traduzido por Maria Luiza X. de A. Borges. Rio de Janeiro: Jorge Zahar, 2003.

2. Lévy, P. Ciberdemocracia. Tradução de Alexandre Emílio. Lisboa: Instituto Piaget, 2002.

3. Elsa, E.; Nuno, V. L.; Timasz, J. Smart sustainable cities reconnaissance study. United Nations University - UNU-EGOV, 2016.

4. Rifkon, J. A Terceira Revolução Industrial - Como o poder lateral está transformando a energia, a economia e o mundo. São Paulo: M. Books do Brasil, 2012.

5. European Union. Mapping Smart Cities in the EU. Policy Department: Economic and Scientific Policy. 2014.

6. Van, B. B. "Digital cities and transferability of results". In: Proceedings of the 4th EDC Conference on Digital Cities, Salzburg, october 29 \& 301998 , pp. 61-70.

7. ONU News. "População mundial atingiu 7,6 bilhões de habitantes". Disponível via URL <http://www.unmultimedia.org/radio/portuguese/2017/06/populacao-mundial-atingiu-76-bilhoes-de-habitantes/\#. WnSHqK6nFQI>. Acesso em 20.jan.2018.

8. Segundo estudos do IBGE, a população brasileira vivendo em cidades cresce visivelmente, de acordo com medições realizadas de 1991 a 2010. Fonte:IBGE <https://mapas.ibge.gov.br/tematicos/demografia〉.

9. Aristóteles. A política. Rio de Janeiro: Martins Fontes, 2006. (Coleção Clássicos da Filosofia. Edição 3).

10. Os Media Labs reúnem equipes multidisciplinares, em pesquisas interdisciplinares e metodologias transdisciplinares. 
11. Davis, J. "Pesquisador do MIT defende fim da barreira entre arte e ciência". Folha de S.Paulo. Disponível via URL <https://www1.folha. uol.com.br/ilustrissima/2018/02/pesquisador-do-mit-defende-fimda-barreira-entre-arte-e-ciencia.shtml>. Acesso em 02.fev.2018.

12. https://www.media.mit.edu/

13. zkm.de

14. Vários desses laboratórios publicam suas produções. O Media Lab MIT disponibiliza algumas de suas publicações pela internet 〈https://www.media.mit.edu/search/?filter=publication〉, além de publicar pela The MIT Press. O Media Lab / UFG disponibiliza suas publicações online pelo site e também em endereço específico 〈https://producao.ciar.ufg.br/ebooks/invencoes/〉. O ZKM também possui linha editorial própria 〈https://zkm.de/en/publications〉, para citar alguns.

15. http://medialab-prado.es/

16. http://medialabbrasil.com/

17. https://www.medialab.ufg.br/

18. https://medialab.unifesspa.edu.br/

19. https://www.medialab.ufg.br/p/18689-media-lab-unb

20. Fonseca, A. "Laboratorios sociales y ciudadanos". In: labSurlab + Co-operaciones. Medelín: Co-operaciones, 2012.

21. A afirmação é do jornal Diário da Manhã, edição de 25/out/2016. 〈http://impresso.dm.com.br/edicao/20161025/pagina/1〉. Acesso em 25.out.2016.

22. https://medialab.aalto.fi/

23. O sistema foi implementado pelas Universidade de Brasília, Universidade Federal de Goiás e Universidade Federal do Piauí, em 2010. Prêmio Edital XPTA; LAB 2009, do Ministério de Cultura e da Sociedade dos Amigos da Cinemateca de São Paulo. Disponível em: wikinarua. com. Acesso em 10 de fev. 2018.

24. Participam deste trabalho Cleomar Rocha (coordenador e responsável pela concepção dos projetos), Hugo Nascimento, Ravi Passos, Lina Lopes, Luma Oliveira, Mateus Sperandio, Hugo Camargo, Renato Mesquita, Kaiky Fernandez, Evandro P. Braga e Wilder Fioramonte.

25. Autores: Claudia Loch, Felipe Modesto, Francisco de Paula Barretto, Ronaldo Ribeiro da Silva, Renato Perotto, Suzete Venturelli e Victor Valentim. Apoio: Camille Venturelli Pic. Disponível em: https:/ciurbi. wordpress.com/. Acesso em 14 de fev. 2018.

26. Venturelli, S. Arte computacional. Brasília: EDUNB, 2017.

27. Coordenação: Suzete Venturelli, equipe: Breno Rocha, Tiago Coelho e Bruno Ribeiro, 2009.

28. Realizado de 2011 a 2013, Media Lab / UnB, com a participação de Suzete Venturelli, Francisco de Paula Barretto, Claudia Loch, Ana Lemos, Juliana Hilário, Camille Venturelli Pic, Bruno Ribeiro, Victor Valentim, Hudson Bomfim, entre outros. Disponível em: 〈https://geopartitura.wordpress.com/>. Acesso em: 4 abr. 2016.

29. Rocha, C. Pontes, janelas e peles: cultura, poéticas e perspectivas das interfaces computacionais. $2^{a}$ ed. Goiânia: Funape/Media Lab/Ciar/ UFG, 2017. (Coleção Invenções).

\section{ARTECIENGIA UM RETRATO AGADEMGO BRASILEIRO}

\author{
João Ricardo Aguiar da Silveira, \\ Roger F. Malina e Denise Lannes
}

INTRODUÇÃO As definições de arte e ciência têm passado por permanentes transformações ao longo da história e já foram praticamente indistinguíveis no início da história da filosofia ocidental. Entre aproximações e distanciamentos, o período do Renascimento marca um dos momentos mais importantes para a união dessas áreas no Ocidente através de trabalhos como os de Brunelleschi, Pisanello, da Vinci, Dürer e até mesmo Galileu [1]. Nos séculos XVI e XVII o raciocínio dedutivo de René Descartes e o método indutivo de Francis Bacon são marcos para o progresso da ciência e também para o início do distanciamento entre ciência e arte. No mesmo período, Isaac Newton, que anteriormente fora adepto do misticismo, religião e alquimia, escreve suas teorias que trazem uma nova compreensão do mundo a partir de uma visão matemática e lógica [2]. Embora nunca estivessem definitivamente separadas, o ápice do distanciamento entre as áreas parece ocorrer no século XIX, quando, segundo Martins [3, p.4], o positivismo busca "eliminar o simbólico do domínio científico”.

Depois de longo período de afastamento, há uma série de indicações que apontam para uma intensa (re)aproximação entre arte e ciência na contemporaneidade. Em diferentes países foram criados e consolidados diversos espaços institucionais dedicados à pesquisa eà realização de projetos que integram essas áreas. Alguns exemplos são: Symbiotica, da Universidade do Oeste da Austrália; Art|Sci Center, da Universidade da Califórnia, Los Angeles (UCLA); Le Laboratoire, da Universidade de Harvard e o The Ars Electronica Center, na Áustria. No portal da Leonardo / Sociedade Internacional para as Artes, Ciência e Tecnologia (Leonardo/ISAST) [4] está disponível um link o qual fornece informações sobre a ampla e crescente rede de pessoas e instituições nessa área ao redor do mundo.

A publicação Art-Science: an annotated bibliography [5] distingue os 16 trabalhos considerados pontos de partida para compreensão do momento de crescimento do campo da arte-ciência-tecnologia. Destaca-se, também, a produção de livros dedicados ao público não especializado, tais como Visualizations: the nature book of art and science bibliography [6], Art and science [7], Seen| unseen: art, science, and intuition from Leonardo to the Hubble telescope [8], Artscience: creativity in the post-Google generation [9], Art and science [10], Art + science now [11], Colliding worlds: how cutting-edge science is redefining contemporary art [12], Reductionism in art and brain science: bridging the two cultures [13].

No Brasil, na década de 1990, pesquisadores como Leopoldo de Meis e Tânia de Araújo-Jorge, da área das ciências da vida, aproxi- 